\title{
Use of Long-Term Microdialysis Subcutaneous Glucose Monitoring in the Management of Neonatal Diabetes
}

\author{
A First Case Report
}

\author{
Andreas Holzinger ${ }^{a}$ Walter Bonfig ${ }^{a}$ Beate Kusser ${ }^{a}$ Thomas Eggermann $^{b}$ \\ Herbert Müller $^{c}$ Hans-Georg Münch ${ }^{a}$ \\ ${ }^{a}$ Dr. von Hauner Children's Hospital, Ludwig Maximilians University Munich; ' Institute of Human Genetics, \\ University Hospital, Aachen, and ${ }^{\mathrm{c}}$ Department of Pediatrics, Klinikum Kempten-Oberallgäu, Kempten, Germany
}

\section{Key Words}

Neonatal diabetes · Microdialysis · Insulin

\begin{abstract}
In neonatal diabetes mellitus (NDM), a rare genetic disorder, insulin therapy is required but the management is difficult. Frequent blood glucose determinations are necessary in most cases. Microdialysis subcutaneous glucose monitoring (MSGM) is feasible in neonates and has been proposed to reduce painful blood sampling and blood loss. We have applied long-term MSGM to a smallfor-date female newborn with transient NDM. We found a good correlation of subcutaneous and blood glucose concentration over a wide range of values. MSGM enabled a reduction in blood glucose determinations during optimization of intravenous insulin treatment and initiation of continuous subcutaneous insulin infusion. We conclude that long-term MSGM is feasible and may reduce painful blood sampling and blood loss in NDM. Furthermore, long-term MSGM may hold a potential for avoiding hypoglycemic episodes and earlier discharge.
\end{abstract}

Copyright (๑) 2006 S. Karger AG, Basel

\section{Introduction}

Neonatal diabetes mellitus (NDM) is a rare entity with an incidence of 1 in 400,000 neonates [1,2]. More than $50 \%$ of cases are classified as transient NDM (TNDM) [3, 4]. Typically, uniparental paternal isodisomy of chromosome 6 (UDP6), paternal duplications or methylation defects at Chr 6q24 are found in TNDM [5]. Insulin therapy has to be initiated and remission occurs within a few months to up to 2 years. Recently, the use of continuous subcutaneous insulin infusion (CSII) has been reported to be safe, more physiological and more accurate than injections [1]. The management of NDM with insulin, however, is difficult with a significant risk of hypoglycemic episodes [1]. Long-term microdialysis subcutaneous glucose monitoring (MSGM) is feasible in humans [6] and its use in newborns has been reported [7]. Such systems continuously perfuse dialysis fluid through a semipermeable subcutaneous catheter and recollect the dialysate for point-of-care analysis. A good correlation between subcutaneous and blood glucose levels was observed in newborns and the procedure was suggested to reduce painful blood sampling and blood loss [8].

\section{KARGER}

Fax +41613061234 E-Mail karger@karger.ch www.karger.com
Andreas Holzinger, MD

Dr. von Hauner Children's Hospital, Ludwig Maximilians University

Lindwurmstrasse 4, DE-80337 Munich (Germany)

Tel. +49895160 2811, Fax +498951607751

E-Mail andreas.holzinger@med.uni-muenchen.de 
Table 1. Capillary blood glucose determinations and hypoglycemic episodes during different phases of insulin treatment in a patient with neonatal diabetes

\begin{tabular}{|c|c|c|c|c|c|}
\hline Mode of treatment and diagnostics & $\begin{array}{l}\text { Day } \\
\text { of life }\end{array}$ & $\begin{array}{l}\text { Total } \\
\text { hours }\end{array}$ & $\begin{array}{l}\text { Blood glucose } \\
\text { determina- } \\
\text { tions }\end{array}$ & $\begin{array}{l}\text { Blood glucose } \\
\text { determinations } \\
\text { per } 24 \mathrm{~h} \text { (range) }\end{array}$ & $\begin{array}{l}\text { Hypoglycemic } \\
\text { episodes } \\
\text { (per } 24 \mathrm{~h} \text { ) }\end{array}$ \\
\hline Initial intravenous insulin (demand feeding) & $5-13$ & 195 & 121 & $14.9(10-24)$ & $6(0.74)$ \\
\hline Intravenous insulin; fixed feeds every $3 \mathrm{~h}$ & $13-20$ & 173 & 134 & $18.6(16-23)$ & $6(0.83)$ \\
\hline Intravenous insulin and MSGM & $20-28$ & 187 & 74 & $9.5(8-11)$ & $2(0.26)$ \\
\hline CSII and MSGM & $28-31$ & 68 & 27 & $9.5(8-10)$ & 0 \\
\hline CSII without MSGM & $31-44 *$ & 296 & 87 & $7.05(6-11)$ & 0 \\
\hline
\end{tabular}

* Day of discharge.

We report here on a small-for-gestational-age (SGA) newborn with TNDM due to paternal UPD6. During initial intravenous insulin treatment and the transition to CSII, we used long-term MSGM. This is the first report of MSGM in the management of neonatal diabetes.

\section{Research Design and Methods}

After an uneventful pregnancy, the female fetus was delivered at term by caesarean section. Birth weight was $2.75 \mathrm{~kg}(1.8 \mathrm{th}$ percentile, $-2.1 \mathrm{SD})$, body length was $47 \mathrm{~cm}$ (1.9th percentile, $-2.1 \mathrm{SD}$ ). Blood glucose was $2.8 \mathrm{mmol} / \mathrm{l} 90 \mathrm{~min}$ after birth and $6.9 \mathrm{mmol} / \mathrm{l}$ at $19 \mathrm{~h}$. Generalized edema and inappropriate sucking were observed. On day 4, body weight was $2.31 \mathrm{~kg}$ and preprandial blood glucose was continuously rising to $13.3 \mathrm{mmol} / \mathrm{l}$. On day 5 , when blood glucose was $23.8 \mathrm{mmol} / 1$, administration of intravenous insulin was initiated at a basal rate of $0.03 \mathrm{IU} / \mathrm{kg} \cdot \mathrm{h}$. Intravenous boluses were administered according to capillary blood glucose concentrations and demand feeding. Management was difficult and episodes of hypoglycemia (blood glucose $<2.6 \mathrm{mmol} / \mathrm{l}$ ) occurred. On day 13 the patient was transferred to our neonatal intensive care unit. Blood glucose management remained unsatisfactory. Informed consent was obtained from the parents to initiate subcutaneous microdialysis and to perform genetic analyses. Screening for paternal UDP6 was performed by typing of microsatellite markers (D6S276, D6S1010, D6S308, D6S311, D6S430, D6S265).

Starting from postnatal day 20, MSGM was performed using a CMA 70 microdialysis catheter and a CMA 106 pump. Bedside analyses were performed on a CMA 600 Microdialysis Analyzer (CMA/Microdialysis AB, Solna, Sweden). The microdialysis procedure and point-of-care glucose analyses of the dialysate were performed as described previously [8]. Briefly, the microdialysis catheter was introduced into subcutaneous adipose tissue of the lateral thigh after transdermal local anesthesia with a 24-gauge intravenous catheter. The steel and plastic cannulas were withdrawn such that only the semipermeable tip of the microdialysis catheter $(0.6$ $\times 10 \mathrm{~mm}$ ) remained in the subcutaneous tissue. A maximum residing time of an individual catheter was defined as 1 week. The catheter was fixed to the patient's skin with a transparent adhesive foil and the portable pump (flow rate: $0.3 \mu \mathrm{l} / \mathrm{min}$ ) and a collecting microvial were connected. The nursing staff was instructed to replace the collecting microvial every $15 \mathrm{~min}$ and to perform bedside analysis of the dialysate. Blood glucose measurements in a clinical chemistry laboratory by an enzymatic method on an automated analyzer (ESAT 6660, Eppendorf, Hamburg, Germany) or bedside with a HemoCue B glucose analyzer (HemoCue, Grossostheim, Germany) were performed when believed necessary for clinical management. Microdialysis data were accessible to the clinician immediately. Abnormal MSGM values prompted blood glucose measurements.

CSII with a H-Tron ${ }^{\circledR}$ plus pump (Disetronic, Burgdorf, Switzerland) was initiated on day 28 with a basal rate of 0.02 IU insulin/ $\mathrm{kg} \cdot \mathrm{h}$ and boluses for meals and correction of hyperglycemia. MSGM was continued until day 31 .

\section{Results}

Typing of microsatellite markers revealed paternal UPD6 in our patient. The identity of the samples was confirmed by microsatellite markers on other chromosomes. C-peptide (measured at day 28 of life) was below detection limit $(<0.5 \mathrm{ng} / \mathrm{ml})$.

During the initial week of intravenous insulin treatment with conventional capillary blood glucose monitoring, the number of hypoglycemic episodes was high and remained high during the second week despite changing to fixed 3-hourly feeds and more intensive blood glucose monitoring (table 1). When MSGM was introduced during intravenous insulin treatment in the 3 rd week of treatment the number of blood glucose determinations decreased while less hypoglycemic episodes were recorded (table 1). MSGM was continued during the transition to CSII. During this 4-day phase and the following 2 weeks, no hypoglycemia was observed. After finding a suitable 
Fig. 1. Example of correlation of blood glucose and microdialysis glucose concentrations. During a 64-hour interval while intravenous insulin was administered, blood glucose values were reliably reflected by microdialysis measurements over a wide range of concentrations (correlation coefficient $r=0.91$ ). Note that due to the high frequency of microdialysis measurements, rising glucose levels with meals every $3 \mathrm{~h}$ are easily recognizable.

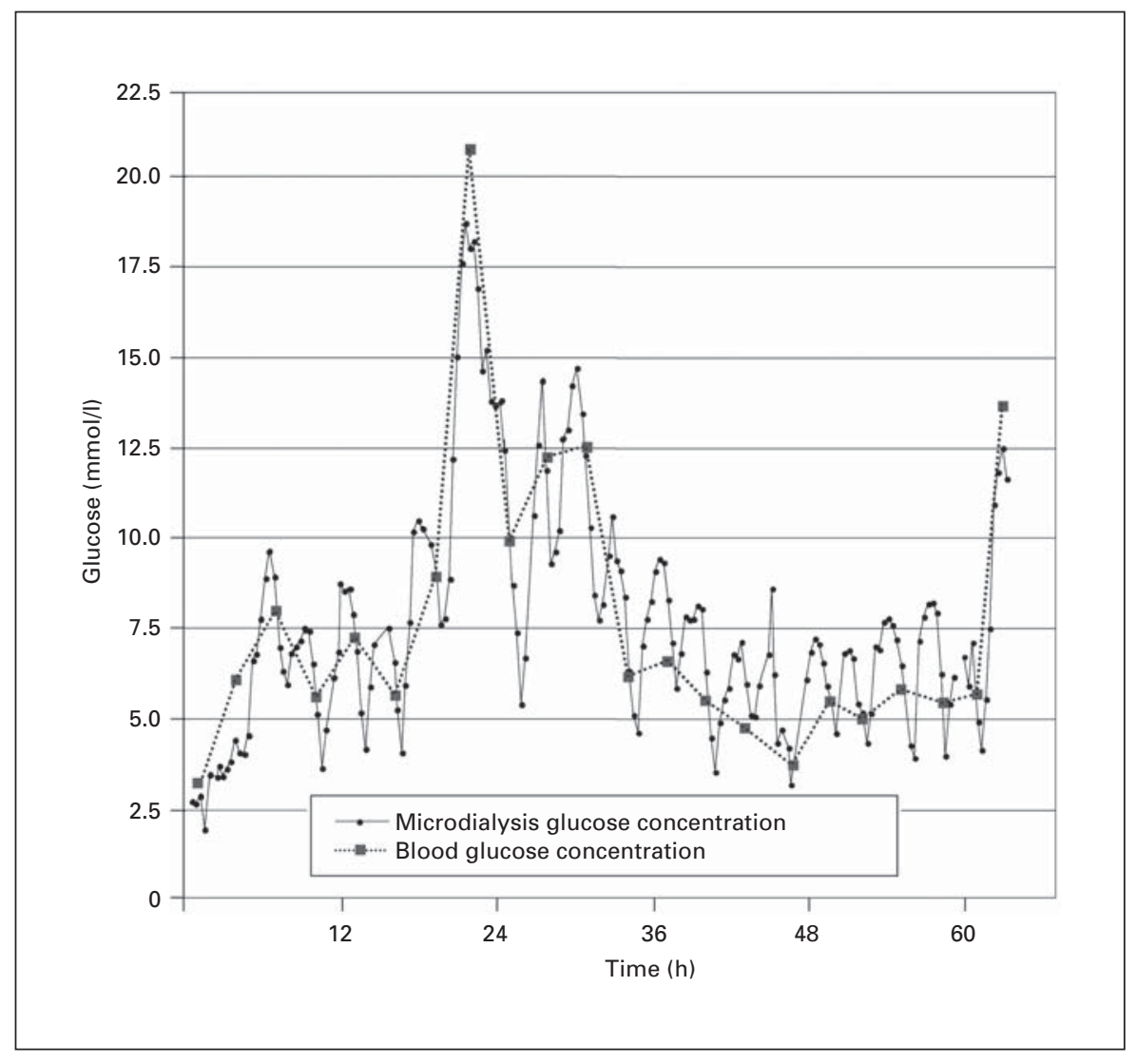

treatment mode, MSGM was discontinued on day 31 of life. For a total of 12 days of MSGM, 3 microdialysis catheters had to be introduced. One catheter was found displaced because of the infant's activity. Another catheter was removed immediately after positioning because of inadvertent puncture of a small vein since blood clots surrounding the catheter are expected to inhibit free equilibration of extracellular and microdialysis fluids. No local complications were observed. The mean number of blood glucose measurements remained low during the following 2-week period (table 1). After thoroughly instructing the parents, the patient was discharged on day 44 .

Outpatient follow-up demonstrated decreasing insulin demand. At age $3^{1 / 2}$ months, remission occurred and insulin treatment was discontinued. Adequate weight gain was observed during and after insulin therapy. At age 6 months, body weight was $7.4 \mathrm{~kg}$ (72nd percentile), body length was $64 \mathrm{~cm}$ (16th percentile). HbA1C was $4.8 \%$. Overall development was normal.

\section{Conclusions}

Neonatal diabetes represents a challenge for therapeutic management. Hypoglycemic episodes are likely to occur [1] and many painful blood sampling procedures appear necessary. In a case with transient neonatal diabetes, we demonstrated that long-term MSGM is feasible. Reduced subcutaneous tissue mass in a SGA newborn was not relevant for microdialysis function. A good correlation of subcutaneous and blood glucose concentration over a wide range of values (fig. 1) enabled early detection of rising and falling blood glucose and allowed therapeutic interventions. MSGM enabled a reduction in blood glucose determinations during optimization of intravenous insulin treatment and initiation of CSII.

Studies are needed to address whether long-term MSGM reduces painful blood sampling and blood loss as compared to conventional management. Moreover, the use of MSGM may hold a potential for better blood glucose control and earlier discharge of a newborn with diabetes mellitus. 


\section{References}

1 Polak M, Shield J: Neonatal and very-earlyonset diabetes mellitus. Semin Neonatol 2004; 9:59-65.

2 Shield JP: Neonatal diabetes: new insights into aetiology and implications. Horm Res 2000; 53(suppl 1):7-11.

3 Shield JP, Gardner RJ, Wadsworth EJ, Whiteford ML, James RS, Robinson DO, Baum JD, Temple IK: Aetiopathology and genetic basis of neonatal diabetes. Arch Dis Child Fetal Neonatal Ed 1997;76:F39-F42.
4 Von Mühlendahl KE, Herkenhoff H: Longterm course of neonatal diabetes. $\mathrm{N}$ Engl J Med 1995;333:704-708.

5 Metz C, Cave H, Bertrand AM, Deffert C, Gueguen-Giroux B, Czernichow P, Polak M: Neonatal diabetes mellitus: chromosomal analysis in transient and permanent cases. $\mathrm{J}$ Pediatr 2002;141:483-489.
6 Lonnroth P, Jansson PA, Smith U: A microdialysis method allowing characterization of intercellular water space in humans. Am J Physiol 1987;253:E228-E231.

7 Horal M, Ungerstedt U, Persson B, Westgren M, Marcus C: Metabolic adaptation in IUGR neonates determined with microdialysis - a pilot study. Early Hum Dev 1995;42:1-14.

8 Baumeister FA, Rolinski B, Busch R, Emmrich P: Glucose monitoring with long-term subcutaneous microdialysis in neonates. Pediatrics 2001;108:1187-1192. 